\title{
Pink hypopyon in a patient with Serratia marcescens corneal ulceration
}

\author{
James A Stefater, Durga S Borkar and James Chodosh
}

\begin{abstract}
A 65-year-old woman presented to the emergency ward at the Massachusetts Eye and Ear Infirmary with 2 days of redness, irritation, photophobia, and diminished vision in her left eye. She was found to have a large central corneal ulcer with a small hypopyon. On the following day, after initiation of broad-spectrum antibiotics, the patient had improved symptoms but now had a 2-mm hypopyon that was distinctly pink in color. Cultures were positive for Serratia marcescens. A pink hypopyon, a rare occurrence, alerted the authors to a causative agent of Enterobacteriacae, either Klebsiella or Serratia. Immediate and intensive treatment was subsequently initiated.
\end{abstract}

Keywords: Corneal ulcer; Pink hypopyon; Serratia marcescens

A 65-year-old woman presented to the emergency ward at the Massachusetts Eye and Ear Infirmary with 2 days of redness, irritation, photophobia, and diminished vision in her left eye. She wore soft contact lenses but noted that she had not worn her lenses for the last 3 days. She also described a prior history of ocular herpes simplex virus in both eyes which last flared 7 months prior to her presentation. She noted compliance with her prophylactic oral acyclovir $400 \mathrm{mg}$ twice daily. Her other medical problems include lumbar disk herniation, hypertension, gastroesophageal reflux disease, and cirrhosis secondary to alcohol use.

On exam, the patient was found to have normal vital signs. Her best corrected visual acuities were 20/40 in the right eye and 20/300 in the left eye. Anterior examination of her right eye was unremarkable except for a mild nuclear sclerotic and cortical cataract. On the left, she was noted to have erythema and tenderness of her eyelids with $3+$ diffuse conjunctival injection. She had a soft contact lens in place in the left eye. The patient did not know there was a contact lens retained in her left eye. Slit lamp biomicroscopy of the left eye revealed diffuse corneal edema with a large pericentral epithelial defect $(5.2 \times 2.7 \mathrm{~mm})$ with three small focal areas of infiltration measuring less than $1 \mathrm{~mm}, 4+$ cell and flare, and a 1-mm hypopyon. The rest of the exam was unremarkable. At this time, the patient was presumed to

\footnotetext{
* Correspondence: James_Chodosh@meei.harvard.edu

Department of Ophthalmology, Massachusetts Eye and Ear Infirmary, Harvard Medical School, 243 Charles Street, Boston, MA 02114, USA
}

have contact lens-related keratitis with concern for herpes simplex virus reactivation. A corneal scraping was performed for gram and calcofluor white stains and cultures, and the contact lens was also cultured. The patient was started on acyclovir $400 \mathrm{mg}$ PO five times daily, cyclopentolate three times daily, fortified vancomycin $25 \mathrm{mg} / \mathrm{ml}$ every hour, and tobramycin $14 \mathrm{mg} / \mathrm{ml}$ every hour.

Upon return the following day, the patient was found to have improved symptoms but unchanged visual acuity. Exam revealed an improving epithelial defect and diffuse corneal stromal haze with moderate folds in Descemet's membrane. The patient now had a 2-mm hypopyon that was distinctly pink in color (Figure 1). Cultures were subsequently positive for Serratia marcescens from both the corneal scrapings and the retained contact lens.

In a recent report, S. marcescens makes up about $10 \%$ of culture isolates in bacterial keratitis [1]. Initially, we presumed that the pink nature of the hypopyon was secondary to coincident red blood cells with the leukocyte infiltrate. However, several reports have demonstrated an association between certain bacterial species and a specific color of intraocular infiltration. A pink hypopyon was first reported as a sign of $S$. marcescens endophthalmitis [2]. A subsequent report also identified Klebsiella pneumonia endophthalmitis as a cause of pink hypopyon [3]. Interestingly, the $S$. marcescens bacterium has been known for many years to produce a red pigment (prodigiosin). The red pigment has been identified in tooth abscesses and in the urine of patients with urinary tract infections $[3,4]$.

\section{Springer}




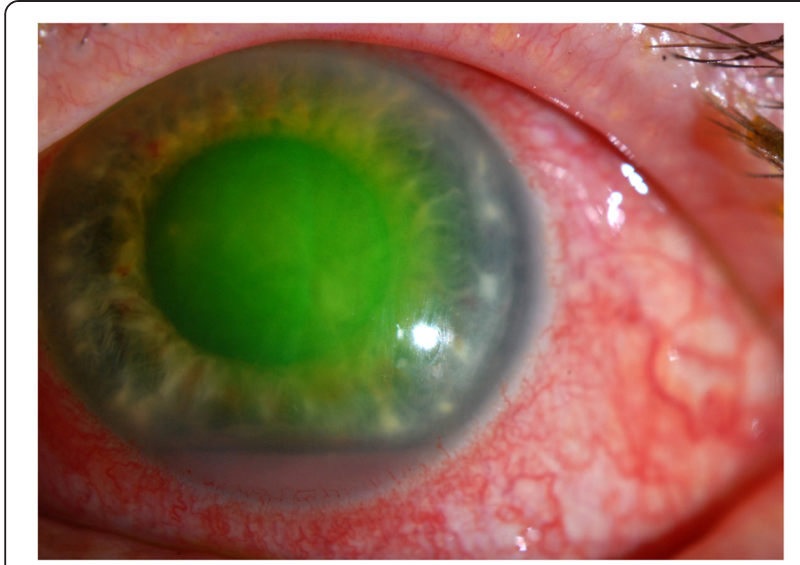

Figure 1 The patient's left eye demonstrating a pink hypopyon in the presence of fluorescein staining.

In this report, we describe a case of a pink hypopyon caused by a contact lens-related corneal ulcer. Our patient responded well to immediate and intensive treatment with fortified aminoglycosides. A pink hypopyon should alert the physician to a causative agent that includes Enterobacteriacae, either Klebsiella or Serratia, and can occur in relation to contact lens over-wear.

\section{Consent}

Written informed consent was obtained from the patient for the publication of this report and the accompanying image.

\section{Competing interests}

The authors declare that they have no competing interest.

\section{Authors' contributions}

JAS, DB, and JC conducted the clinical diagnosis and decision-making. All authors read and approved the final manuscript.

\section{Acknowledgements}

None.

Received: 31 December 2014 Accepted: 19 March 2015

Published online: 31 March 2015

\section{References}

1. Kowalski RP, Kowalski TA, Shanks RM, Romanowski EG, Karenchak LM, Mah FS (2013) In vitro comparison of combination and monotherapy for the empiric and optimal coverage of bacterial keratitis based on incidence of infection. Cornea 32:830-834

2. Al Hazzaa SA, Tabbara KF, Gammon JA (1992) Pink hypopyon: a sign of Serratia marcescens endophthalmitis. Br J Ophthalmol 76:764-765

3. McEntegart MG, Porterfield JS (1949) Bacteremia following dental extractions. Lancet ii:596-598

4. Kass EH, Schneiderman LJ (1957) Entry of bacteria into the urinary tracts of patients with inlaying catheters. N Engl J Med 256:556-557

\section{Submit your manuscript to a SpringerOpen ${ }^{\circ}$ journal and benefit from:}

- Convenient online submission

- Rigorous peer review

- Immediate publication on acceptance

- Open access: articles freely available online

- High visibility within the field

- Retaining the copyright to your article

Submit your next manuscript at $>$ springeropen.com 